\title{
Working in small-scale, homelike dementia care: effects on staff burnout symptoms and job characteristics. A quasi-experimental, longitudinal study
}

Journal of Research in Nursing 2018, Vol. 23(2-3) 109-122

(C) The Author(s) 2018

Reprints and permissions: sagepub.co.uk/journalsPermissions.nav DOI: I0.II77/I744987।I8757838 journals.sagepub.com/home/jrn

@SAGE

\section{Sandra MG Zwakhalen}

Full Professor, CAPHRI School for Public Health and Primary Care, Maastricht University, the Netherlands

\section{Jan PH Hamers}

Full Professor, CAPHRI School for Public Health and Primary Care, Maastricht University, the Netherlands

\section{Erik van Rossum}

Assistant Professor, CAPHRI School for Public Health and Primary Care, Maastricht University, the Netherlands; Assistant Professor, Zuyd University of Applied Sciences, Heerlen, the Netherlands

\section{Ton Ambergen}

Assistant Professor, CAPHRI School for Public Health and Primary Care, Maastricht University, the Netherlands

\section{Gertrudis IJM Kempen}

Full Professor, CAPHRI School for Public Health and Primary Care, Maastricht University, the Netherlands

\section{Hilde Verbeek}

Assistant Professor, CAPHRI School for Public Health and Primary Care, Maastricht University, the Netherlands 


\begin{abstract}
Aim: This paper reports on a quasi-experimental, longitudinal study on the effects of working in a new type of dementia care facility (i.e. small-scale living facilities) on staff burnout symptoms and job characteristics (job autonomy, social support, physical demands and workload).

Methods: It is hypothesised that nursing staff working in small-scale facilities experience fewer burnout symptoms, more autonomy and social support, and fewer symptoms of physical demands and workload compared with staff in regular wards. Two types of long-term institutional nursing care settings were included: 28 houses in small-scale living facilities and 21 regular psychogeriatric wards in nursing homes. At baseline and at follow-ups after 6 and 12 months nursing staff were assessed by means of self-report questionnaires. In total, 305 nursing staff members were included in the study, II4 working in small-scale living facilities (intervention group) and 191 in regular wards (control group).

Results: No overall effects on burnout symptoms were detected. Significantly fewer physical demands and lower workload were experienced by staff working in small-scale living facilities compared with staff in regular wards. They also experienced more job autonomy. No significant effect was found for overall social support in the total group.

Conclusions: This study suggests positive effects of the work environment on several work characteristics. Organisational climate differs in the two conditions, which might account for our results. This may influence nursing staff well-being and has important implications for nursing home managers and policy makers. Future studies should enhance our understanding of the influence of job characteristics on outcomes.
\end{abstract}

\title{
Keywords
}

burnout, long-term care, nursing home, nursing staff, small-scale living facilities, staff well-being

\section{Introduction}

Long-term institutional nursing home care for people with dementia is shifting in terms of philosophy and practice from a medically-oriented care environment towards a residentcentred, individualised care environment (White-Chu et al., 2009). The worldwide trend towards deinstitutionalisation fits within this shift. When the dementia progresses and care demands increase, admission to a long-term care facility often becomes inevitable. In the Netherlands, long-term psychogeriatric care is increasingly organised in small-scale living facilities (Verbeek et al., 2009b), and as many as a quarter of the people with dementia live in small-scale facilities (Te Boekhorst et al., 2007; Wimo and Morthenson Ekelof, 2004).

These facilities emphasise the importance of well-being and differ from regular wards with respect to physical, social and organisational characteristics (Ausserhofer et al., 2016; Verbeek et al., 2009b). Small-scale living facilities aim to offer a homelike environment to a small number of 8-10 residents per group. Small-scale living facilities focus strongly on normal daily life. Residents are encouraged to participate in meaningful activities that are often centred around the daily household (e.g. washing and folding clothes, cooking and cleaning) within a homelike environment. The daily life is determined together by residents, their family caregivers and nursing staff. This is opposed to 
traditional large nursing homes, in which routines dominate the daily lives of the nursing home residents and which often have an institutionalised hospitalised character (Verbeek et al., 2009b).

Incentives and increased awareness of older persons' needs has supported the worldwide development of these new care settings (Annerstedt, 1993; Eliopoulos, 2010; Kane et al. 2007). The fact that healthcare policy needs to be evidence-based has received worldwide attention and support (Niessen et al., 2000). However, small-scale living facilities were one of the developments implemented with little convincing scientific evidence.

Nursing staff employed in small-scale living facilities have different roles and tasks compared with staff employed in more traditional facilities. Overall, staff working in small-scale living facilities incline more towards integrated care: nursing staff members are part of the household and have integrated tasks, including personal and medical care, organising activities and daily household chores (Kane et al., 2007; Te Boekhorst et al., 2007; Verbeek et al., 2009b). Studies indicate that this may affect job characteristics such as autonomy, social support, workload and demands (Adams et al., 2017; Willemse et al., 2014). For example, in small-scale living facilities daily nursing activities are characterised by working all-round and independently, whereas nursing staff in traditional wards collaborate with each other and have differentiated tasks. Autonomy and social skills specifically were regarded as important by nursing staff working in small-scale living facilities in comparison with traditional nursing homes (Adams et al., 2017).

Despite the increase of small-scale facilities, relatively little is known about the effects of work environments on nursing staff well-being (such as job stress) and job characteristics (Ausserhofer et al., 2016). The few studies that have focused on staff well-being in small-scale living in comparison with regular wards (Alfredson and Annerstedt, 1994; Reggentin and Dettbarn-Reggentin, 2004; Te Boekhorst et al., 2008) showed that working in small-scale living facilities may offer nursing staff attractive work and a favourable work environment (Vermeerbergen et al., 2017). Although most of the studies showed some positive effects on job characteristics, like autonomy and workload, study findings on burnout symptoms were inconsistent. Methodological flaws (i.e. cross-sectional designs) complicate the interpretation of findings.

It is important to be aware of the impact of the staff work environment and how this influences nursing job stress and care for residents (Norbergh et al., 2002). Environmental and organisational aspects have been reported as being important in relation to burnout (Benjamin and Spectator, 1990) and the provision of person-centred care (Willemse et al., 2015). In turn, low levels of burnout and work environment attributes impact on quality of care (Aström et al., 1991; Temkin-Greener et al., 2010). Furthermore, there is growing evidence that residents' quality of life is positively related to non-patient-related factors such as organisational climate (Mattiasson and Andersson, 1995) and nursing staff job characteristics (Chou et al., 2002; Edvardsson et al., 2008; Rosen et al., 2005). Positive associations between the non-institutional environment and staff morale were mentioned by Parker et al. (2004).

The research question of the present study is: What is the effect of working in small-scale living facilities on staff burnout symptoms and various job characteristics (job autonomy, social support, physical demands and workload)? These job characteristics were selected since they are mentioned by many theoretical models of stress as important factors in relation to outcomes such as nurses' job satisfaction and burnout (Karasek, 1985; Kovner et al., 2006). 


\section{Methodology}

\section{Design}

A longitudinal, quasi-experimental study was carried out which compared two types of longterm institutional nursing care settings for people with dementia: small-scale living facilities and regular psychogeriatric wards. The design is described in more detail elsewhere (Verbeek et al., 2009a).

\section{Specifications of the setting}

Nursing home care in the Netherlands. Nursing home care in the Netherlands is provided in dementia-specific wards. The wards can differ in size from small-scale wards (up to 10 residents) to more traditional large-scale wards with up to 30 residents (Verbeek et al., 2009b). Nursing homes in the Netherlands are in general part of non-profit care organisations (Bos et al., 2017). About 350 organisations provide nursing home care in the Netherlands for a total of 129,000 residents (Actiz, 2017). Care provided in nursing homes requires a multidisciplinary approach given the severe care dependency of residents (Verbeek et al., 2009b). Therefore, a multidisciplinary team is employed consisting of nursing staff and allied health professionals such as physiotherapists, psychologists, occupational therapists, dietitians, speech therapists and nursing home physicians (Verbeek et al., 2009b). Residents' families and volunteers are involved in the nursing home care provided.

The two nursing home conditions. All nursing homes that offered small-scale living and were located in the southern part of the Netherlands were eligible to participate in the current study. Managing directors received a written invitation to participate.

In the experimental condition, 28 houses in small-scale living facilities were characterised by the following criteria (Verbeek et al., 2009a):

1. There is a maximum of eight residents per house or unit.

2. Staff, residents and their family form a household together and activities are centred around the daily life and household. Staff perform domestic tasks and prepare meals together with residents and/or their family caregivers.

3. Staff perform integrated tasks, which means that one person may fulfil multiple tasks such as medical and personal care, domestic chores and activities.

4. Residents are cared for by a small, fixed team of nursing staff.

5. Daily life is organised completely or to a large extent by residents, their family caregivers and nursing staff.

6. The archetypal home is a physical setting that resembles a homelike environment.

In the control condition, 21 regular nursing home wards were characterised by the following criteria:

1. There was a minimum of 20 residents per ward.

2. Staff members have differentiated tasks with a main focus on medical and personal care for residents.

3. Residents and their family members have little control over the organisation of daily life within the ward as it is mainly organised around the routines of the nursing home. 


\section{Participants}

Nursing education in the Netherlands is divided into five levels: basic nursing aids (level 1), nursing assistant (level 2), certified nursing assistant (level 3), and registered nurses vocational (level 4) and Bachelor (level 5). All nursing staff (i.e. nursing aids, nursing assistants, certified nursing assistants and registered nurses) directly involved in care tasks and working on a permanent basis in either the selected small-scale living facilities or regular psychogeriatric wards were eligible to participate in the study. Temporary staff (such as trainees), permanent night-shift workers and team managers were excluded from the study as they are known to experience different levels of job stress (Ferri et al., 2016). The total number of eligible staff at baseline was 581; 178 in small-scale living and 403 in regular wards.

\section{Measures and outcomes}

The current study addresses the findings on secondary outcomes including burnout symptoms as an outcome of job stress and job characteristics (job autonomy, social support, workload and physical demands). The findings concerning the primary outcomes are reported elsewhere (Verbeek et al., 2010a). Data on nursing staff were gathered at baseline (T1), and after 6 months (T2) and 12 months of follow-up (T3) by means of selfreport questionnaires.

Burnout symptoms. Burnout symptoms as an outcome of job stress were measured by a fiveitem self-reported questionnaire (De Jonge, 1995). Previous studies determined its validity, reliability and internal consistency (De Jonge, 1995; De Jonge et al., 1993). Current analyses confirmed good internal consistency (Cronbach's alpha $=0.89$ ). Items ranged from 'never' to 'always' on a seven-point Likert scale. The total score ranged theoretically from 5 to 35 . Higher scores indicated more burnout symptoms. A sample item is: 'I feel burned-out by my job.'

Job characteristics. Job characteristics (job autonomy, social support, workload and physical demands) were measured by a self-reported questionnaire. Previous studies determined its validity, reliability and internal consistency (De Jonge, 1995; De Jonge et al., 1993). Current study findings confirmed good internal consistency.

Job autonomy was assessed by the Maastricht Autonomy Questionnaire (MAQ) (De Jonge, 1995), which consists of 10 items scored on a five-point Likert scale ranging from very little to very much. Its total score ranges from 10 to 50 . Higher scores indicate more job autonomy. The questionnaire includes information on job control and freedom in work tasks and methods. It measures the opportunity for staff to determine a variety of task elements, such as the pace of work and the work goals. A sample item is: 'My work offers me the opportunity to interrupt my job whenever I want.' Current study findings confirmed good internal consistency (Cronbach's alpha $=0.90$ ).

Workplace social support was measured by the eight-item scale from the Job Content Questionnaire (De Jonge et al., 2000; Karasek, 1985). The questionnaire inventories workrelated social support, both instrumental and emotional, from colleagues and supervisors. One subscale of four items refers to support from colleagues, whereas the other subscale of four items refers to support by supervisors. It uses a four-point Likert scale with items ranging from 'completely disagree' to 'completely agree'. The total score ranges from 8 to 
32 and a higher score represents more social support. A sample item is: 'My colleagues help get the work done.' Current study findings confirmed good internal consistency of the total scale (Cronbach's alpha $=0.81$ ) and both subscales (Cronbach's alpha, both subscales $=0.85)$.

Workload (psychological demands) was measured by an eight-item scale that includes qualitative and quantitative demanding aspects such as working under time pressure, strenuous work and job complexity (De Jonge, 1995). Items range from 'never' to 'always' on a five-point Likert scale. Total scores range from 8 to 40, with higher scores indicating more symptoms of workload. A sample item is: 'In the unit where I work, work is too complex.' Current study findings confirmed good internal consistency (Cronbach's alpha $=0.91$ ).

Physical demands were assessed by a seven-item questionnaire ranging from 'never' to 'always' on a 5-point Likert scale (De Jonge et al., 1999). A total score is calculated and ranges from 7 to 35 , with higher scores representing more physical demands. Items refer to heavy physical demands like standing and carrying heavy weights. A sample item is: 'In my work, I have to bend forward with my upper body.' Current study findings confirmed good internal consistency (Cronbach's alpha $=0.87$ ).

In addition, the following background variables were assessed: age, gender, education level, months of employment in facility type, years working in elderly care and contract hours per week.

\section{Small-scale environmental characteristics}

A self-developed contrast questionnaire (small-scaled characteristics questionnaire) was used to measure typical environmental characteristics in both the experimental and the control group about the small-scaledness of the facility to see whether the two environments demonstrated enough differentiation. This questionnaire consists of 18 items (scoring range 18-90) that relate to a small-scale unit's organisational, social and physical environment. Higher scores indicate greater adherence to the criteria of small-scale living facilities. A sample item is: 'To what extent are staff and family members part of the household?'

\section{Procedure}

An information leaflet about the study (content and process) including an invitation letter was distributed by the researcher (HV) to all nursing staff of the included wards. The study was further explained during a regular team meeting by the researcher. Nursing staff indicating that they would like to take part were screened for eligibility (not working night shifts or temporarily or as a team manager). Eligible staff were then invited to provide written informed consent before receiving the questionnaire. After 2 weeks a reminder was sent by mail to those who did not respond initially. To guarantee confidentiality, nursing staff returned the questionnaires directly to the researchers using a pre-stamped envelope.

\section{Ethical considerations}

The Medical Ethics Committee (MEC) of the University Hospital Maastricht/Maastricht University approved the study (reference number MEC 07-4-041). In addition, all local 
ethical committees of the participating facilities and the managing directors of the regular nursing homes and small-scale living facilities approved of and provided consent for the study.

\section{Statistical analysis}

All statistical analyses were conducted using Predictive Analytics SoftWare (PASW) version 17 from SPSS. Differences in characteristics between the two groups at baseline were tested with $\chi^{2}$-tests for categorical variables, individual sample $t$-tests for normally distributed continuous variables, and Kruskal-Wallis tests for continuous variables with skewed distributions. A mixed-model multi-level analysis was performed, according to the intention-to-treat principle. All nursing staff with a baseline measurement were included in the analyses, regardless of availability of data at follow-up, since multi-level analyses are robust for missing values in the outcome variables.

All selected background characteristics of participants were included as covariates in the model. Missing data for only these covariates were imputed by multiple imputation. First, fixed effects for group by time interaction were tested for significance. If this interaction was not significant, it was removed from the model and only fixed effects for group and time were tested. All tests used a two-sided significance level of 0.05 .

\section{Results}

\section{Sample}

In total, 305 nursing staff members participated: 114 (response rate 64\%) nursing staff from small-scale living and 191 (response rate 47\%) nursing staff from regular wards. Participants' baseline socio-demographic characteristics are presented in Table 1. Groups were comparable, except that nursing staff members working in small-scale living facilities were

Table I. Characteristics of nursing staff participants.

\begin{tabular}{|c|c|c|}
\hline & $\begin{array}{l}\text { Small-scale living } \\
(n=114)\end{array}$ & $\begin{array}{l}\text { Regular wards } \\
(n=191)\end{array}$ \\
\hline Age in years & 40.7 (II.5) & $42.8(10.1)$ \\
\hline Women ${ }^{\S}$ & $110(97)$ & $170(89)$ \\
\hline \multicolumn{3}{|l|}{ Level of education } \\
\hline Level I, nursing aids & $6(5)$ & $3(2)$ \\
\hline Level 2, nursing assistants & $18(16)$ & $29(15)$ \\
\hline Level 3 , certified nursing assistants & $64(57)$ & $128(67)$ \\
\hline Level $4 \mathrm{RN}$, vocational level & $21(19)$ & $26(14)$ \\
\hline Level 5 RN, Bachelor level & $3(3)$ & $3(2)$ \\
\hline Employment in nursing home type in months* & $23.1(18.4)$ & $85.2(72.8)$ \\
\hline Years working in elderly care & $14.7(10.25)$ & $16.7(10.65)$ \\
\hline Contract hours per week & $26.4(7.0)$ & $26.9(6.6)$ \\
\hline
\end{tabular}

Data are mean (SD) or number (\%).

$\S p=0.021$.

$* p=0.001$. 
Table 2. Unadjusted means (SD) of staff outcomes on burnout symptoms and job characteristics like job autonomy, social support, workload and physical demands.

\begin{tabular}{|c|c|c|c|}
\hline & Baseline & FU 6 months & FU 12 months \\
\hline \multicolumn{4}{|c|}{ Nursing staff ${ }^{\dagger}$} \\
\hline \multicolumn{4}{|c|}{ Burnout symptoms total group (range 5-35) } \\
\hline Small-scale & $12.4(5.0)$ & I $3.0(4.6)$ & $12.7(4.2)$ \\
\hline Regular & $13.4(5.2)$ & $12.3(4.5)$ & $13.2(4.7)$ \\
\hline \multicolumn{4}{|c|}{ Job autonomy (range 10-50) } \\
\hline Small-scale & $30.7(6.5)$ & $29.1(6.8)$ & $29.9(7.7)$ \\
\hline Regular & $26.7(6.8)$ & $26.9(7.6)$ & $26.8(7.5)$ \\
\hline \multicolumn{4}{|c|}{ Social support (range 8-32) } \\
\hline Small-scale & $24.5(3.3)$ & $23.9(3.6)$ & $23.9(3.9)$ \\
\hline Regular ward & $24.1(3.0)$ & $24.1(3.3)$ & $24.4(2.8)$ \\
\hline \multicolumn{4}{|c|}{ Workload (range 8-40) } \\
\hline Small-scale & $23.4(7.1)$ & $25.1(5.8)$ & $24.1(5.2)$ \\
\hline Regular ward & $28.5(5.0)$ & $27.4(4.4)$ & $27.9(4.3)$ \\
\hline \multicolumn{4}{|c|}{ Physical demands (range 7-35) } \\
\hline Small-scale & $19.4(5.3)$ & $20.2(4.9)$ & $20.0(4.9)$ \\
\hline Regular ward & $23.0(4.8)$ & $22.9(4.8)$ & $22.9(4.4)$ \\
\hline
\end{tabular}

†Nursing staff: Baseline $n_{\text {small-scale }}=114, n_{\text {regular wards }}=191$; follow-up (FU) after 6 months $n_{\text {small-scale }}=72, n_{\text {regular }}$ wards $=109$; follow-up after 12 months $n_{\text {small-scale }}=69, n_{\text {regular wards }}=87$.

Higher score indicates more burnout symptoms, autonomy, support, workload and physical demands.

employed for a shorter time and were more often women compared with staff working in regular wards.

A substantial contrast between the two environments (small-scale and regular wards) existed. The mean score of the contrast questionnaire in small-scale wards (67.5; range 60-77) was significantly higher than the mean score of regular wards (42.3; range 36-55), with no overlapping scores (mean difference 25 points; $p<0.001$ ). This contrast remained stable over time (mean difference after 12 months 26 points; $p<0.001$ ).

Unadjusted means on burnout symptoms and job characteristics of overall analyses are presented in Table 2, which shows the number of participants over time. At baseline 114 nursing staff from small-scale living and 191 from regular wards participated. After the 6month follow-up 72 nursing staff from small-scale living and 109 from regular wards participated. After 12 months 69 nursing staff from small-scale living and 87 from regular wards participated. The main reasons for nursing staff non-response were not returning questionnaires, transfer to another ward or nursing home and maternity/sickness leave. Analyses showed that loss to follow-up was not related to nursing staff baseline characteristics.

\section{Effects on burnout symptoms}

No significant effects on burnout symptoms were found in the analyses of the total participants' group (adjusted mean difference 0.72, 95\% confidence interval (CI) -1.19; 2.64, $p=0.458$ ). 


\section{Effects on job characteristics}

Job autonomy. A statistically significant group effect was found for job autonomy (adjusted mean difference $3.88,95 \%$ CI $1.17-6.59 ; p=0.005$ ), demonstrating that nursing staff in small-scale living facilities experienced more job autonomy than staff in regular wards for all measurements. Differences were stable over time.

Social support. No significant effect was found for overall social support in the total participants' group (adjusted mean difference $0.51,95 \%$ CI $0.68-1.71 ; p=0.401$ ). Both groups scored relatively highly on social support.

Additional analyses found a significant effect for social support by co-workers for the total group of participants. Nursing staff in small-scale living facilities experienced more social support from their co-workers than staff in regular wards (adjusted mean difference $0.71 ; 95 \%$ CI $0.16-1.26 ; p=0.012$ ). No significant effects were found for social support by supervisors (adjusted mean difference $0.24 ; 95 \% \mathrm{CI}-0.79 ; 1.26 ; p=0.652$ ).

Workload. A significant group by time interaction was found for workload. In small-scale living facilities, less workload was experienced for all three measurements compared with regular wards. Staff in regular wards reported significantly more workload at baseline (adjusted mean difference 5.25; 95\% CI 2.39-8.11; $p=0.001$ ), after 6 months (adjusted mean difference $3.12 ; 95 \%$ CI $0.31-5.93 ; p=0.030$ ) and after 12 months (adjusted mean difference $4.12 ; 95 \%$ CI $1.27-6.97 ; p=0.005)$ compared with staff in small-scale living facilities.

Physical demands. A significant group effect was found for physical demands. In small-scale living facilities, significantly fewer physical demands were experienced by nursing staff compared with those on regular wards (adjusted mean difference 3.22, 95\% CI 1.27-5.17; $p=0.001)$.

\section{Discussion}

This study examined the effects of working in a new type of dementia care facility (i.e. smallscale living facilities) on staff burnout symptoms and various job characteristics. Differences in job characteristics (e.g. job autonomy, workload and physical demands) were found. Nursing staff working in small-scale, homelike care facilities perceived significantly more autonomy, more social support, less workload and less physical demands. No overall effects were found on burnout symptoms for nursing staff in small-scale living facilities in comparison with traditional nursing homes.

The findings in this study are in line with our previous study findings into the effects of small-scale living facilities on staff well-being by Verbeek et al. (2010a). This study did not demonstrate effects with respect to the outcome measures job satisfaction and motivation in the total group of nursing staff. A recent paper by Adams et al. (2017) also found that the 'dose' of the home likeness seems to impact in a positive way on the job experience of nursing staff.

Previous studies on burnout symptoms comparing both care conditions are mixed. While Reggentin and Dettbarn-Reggentin (2004) found no differences in burnout symptoms, Te Boekhorst et al. (2008) found differences in levels of reported burnout symptoms in favour of nursing staff working in small-scale living facilities. These studies suggested that differences 
in job characteristics (i.e. more job control, fewer demands and more social support) may account for these results (Reggentin and Dettbarn-Reggentin, 2004; Te Boekhorst et al., 2008). Burnout symptoms have been found to be significantly higher in jobs that combine higher demands and lower autonomy (Landsbergis, 1988). The findings of the present study though could not confirm this suggestion. While differences in job characteristics were present for the total group of participants, no differences were found for burnout symptoms.

With regard to job characteristics, in this study nursing staff experienced significantly more autonomy and fewer physical demands and workload in small-scale living facilities compared with staff in regular wards. These findings are consistent with those of other studies, suggesting that demands were lower in small-scale living facilities whereas control/autonomy was higher (Reggentin and Dettbarn-Reggentin, 2004; Te Boekhorst et al., 2008; Vermeerbergen et al., 2017). A process evaluation demonstrated that nursing staff experienced high levels of autonomy in deciding on the day structure (Verbeek et al., 2012). This feeling may partly explain their experience of lower demands and workload. Furthermore, a study by Willemse et al. (2014) stated that staff may experience less interruptions by colleagues providing other services and do not need to deal with their colleagues' time schedules and as a consequence perceive less job demands, which could explain differences.

Although overall analyses in total social support showed no differences, staff working in small-scale living facilities experienced more social support by co-workers. This finding may seem somewhat surprising, since small-scale living facilities offer an environment in which only a small fixed team of nursing staff is responsible for a small group of residents, in contrast to the large teams in regular wards. It might be explained by stronger team cohesion of staff working in these new care environments. Future work should address how these care environments need to be arranged in order to create optimal and efficient working environment conditions for nursing staff.

Some limitations of this study need to be acknowledged. Clearly we need to be careful in interpreting our findings. It remains questionable what causes the differences in nursing staff working in small-scale living facilities compared with regular wards. For most variables notable differences between both care conditions were already observed at baseline and remained consistent over time, therefore no causality could be determined. Personality characteristics of nursing staff may account for differences in job characteristics. A recent study by Pot and De Lange (2010) also suggested that staff characteristics (e.g. age, cultural background) play a role in differences in job characteristics like autonomy. In the current study only a limited number of staff characteristics were included. No information was gathered on ward-related characteristics like management mode, staff ratio and skill mix. Furthermore, although the groups' baseline characteristics were comparable in the present study, except for gender and time of employment in the facility, the groups may differ in terms of other characteristics and/or competences that were not assessed. Staff with specific personal characteristics that make them less likely to perceive high levels of job demands might be more likely to work in living arrangements providing small-scale care. This may have biased our findings. Nursing staff are free to choose a facility to work in and probably choose the type in which they feel most comfortable.

In addition, one might wonder whether there were any differences in the kind of patients cared for in the two different settings. A previous study by Verbeek et al. (2010b) showed 
that residents living in small-scale facilities had a better cognition and functional status compared with residents in regular facilities. However, the findings of the process evaluation (Verbeek et al., 2012) demonstrated that residents' care dependency (more dependent on activities of daily living and cognitive performance) was not mentioned by nursing staff as an important relevant factor. Therefore, we do not think residents' characteristics affected the findings of our current study.

Furthermore, the proportion of non-responders at follow-up was relatively high, and even higher in nursing staff working in regular wards than staff in small-scale facilities. Not returning questionnaires, transfer to another ward or nursing home and maternity/ sickness leave were the main general reasons for non-responding. Insight into the exact reasons for non-responding, however, is lacking. Non-response may be influenced by the social work group cohesion and involvement of small teams working in the small-scale living facilities. Furthermore, it is conceivable that non-responders experienced the highest amount of workload.

\section{Future directions}

More attention should be given to the nursing skills and competences required for working in either one of the care settings. Since this study showed that job-related characteristics differed, other competences may be required. If these can be identified, recruitment and selection of staff would be improved and tailored to the skills of nursing staff. Furthermore, educational programmes could be tailored to train nursing staff for work in small-scale living facilities.

Nursing homes offer complex working environments that are influenced by numerous factors. A leading model, originally developed by Karasek (1985), called the jobdemand-control model, states that two job characteristics (demands and control) influence well-being and job satisfaction. A combination of high job demands and low job control is particularly suggested to have a negative impact such as low job satisfaction. Johnson and Hall (1988) extend the model with social support, since they assume that support received from supervisors and co-workers could buffer the impact of demands and control. In addition, Spoor et al. (2010) mentioned that job resources and recovery opportunities have to match job demands if outcomes are to be optimised. It remains unclear how these can contribute to interventions focusing on improving staff well-being (Spoor et al., 2010). Further research is needed to examine underlying mechanisms for an understanding of possible relationships among working conditions, job characteristics and outcomes such as job satisfaction and burnout and to reveal mediating effects in both nursing home care conditions. In order to have a clear insight into the underlying mechanism it might also be valuable to include measures on individualised (personcentred) care, resident - staff relationships and team climate in future studies especially given the fact that it is well known that team climate is a major determinant of quality of care (Backhaus et al., 2017).

\section{Conclusion}

The findings of this study on job characteristics suggest that organisational climate could differ between both nursing home conditions and may influence nursing staff well-being. This has important implications for nursing home managers and policy makers. In order to 
achieve a healthy work environment for nursing staff it is important to be well aware of nursing staff's experienced well-being, especially since staff well-being may directly influence the quality of nursing home care (Gilloran et al., 1995) since job stress has been linked with turnover rates (Larrabee et al., 2010). Future studies should enhance our understanding of the influence of job characteristics on outcomes.

\section{Key points for policy, practice and/or research}

- This study suggests positive effects of work environment on several job characteristics.

- Nursing staff working in small-scale, homelike facilities experience significantly more autonomy and fewer physical demands and workload compared with staff in regular wards.

- Since this study showed that job characteristics differed, other competences may be required. More attention should be given to the nursing competences required to tailor recruitment and selection of staff and educational programmes to train nursing staff.

- The findings of this study on job characteristics suggest that organisational climate could differ between both nursing home conditions and may influence nursing staff well-being. This has important implications for nursing home managers and policy makers.

- Future studies should enhance our understanding of the influence of job characteristics on outcomes.

\section{Declaration of conflicting interests}

The author(s) declared no potential conflicts of interest with respect to the research, authorship and/or publication of this article.

\section{Ethical approval}

The study design and protocols were approved by the Medical Ethics Committee of the University Hospital Maastricht and Maastricht University (reference number MEC 07-4-041). In addition local ethics Committees of the participating organisations have given consent to the study protocols and procedures.

\section{Funding}

The author(s) disclosed receipt of the following financial support for the research, authorship and/or publication of this article: This work was supported by Maastricht University, the Province of Limburg and five healthcare organisations, all located in the southern part of the Netherlands. Funders had no role in the design, methods, data collections, analysis or preparation of this manuscript.

\section{References}

Actiz (2017) Available at: www.actiz.nl/feiten-en-cijfersoverzicht (accessed 11 September 2017).

Adams J, Verbeek H and Zwakhalen SMG (2017) The impact of organizational innovations in nursing homes on staff

perceptions: A secondary data analysis. Journal of Nursing Scholarship 49(1): 54-62.

Alfredson BB and Annerstedt L (1994) Staff attitudes and job satisfaction in the care of demented elderly people: Group 
living compared with long-term care institutions. Journal of Advanced Nursing 20: 964-974.

Annerstedt L (1993) Development and consequences of group living in Sweden: A new mode of care for the demented elderly. Social Science Medicine 37: 1529-538.

Aström S, Nilsson M, Norberg A, et al. (1991) Staff burnout in dementia care: Relations to empathy and attitudes. International Journal of Nursing Studies 28(1): 65-75.

Ausserhofer D, Deschodt M, De Geest S, et al. (2016) "There's no place like home": A scoping review on the impact of homelike residential care models on resident-, family-, and staff-related outcomes. Journal of the American Medical Directors Association 17(8): 685-693.

Backhaus R, Rossum EV, Verbeek H, et al. (2017) Work environment characteristics associated with quality of care in Dutch nursing homes: A cross-sectional study. International Journal of Nursing Studies 66: 15-22.

Benjamin LC and Spector J (1990) The relationship of staff, resident and environmental characteristics to stress experienced by staff caring for the dementing. International Journal of Geriatric Psychiatry 5: 25-31.

Bos A, Boselie P and Trappenburg M (2017) Financial performance, employee well-being, and client well-being in for-profit and not-for-profit nursing homes: A systematic review. Health Care Management Review 42(4): 352-368.

Chou SC, Boldy DP and Lee AH (2002) Measuring job satisfaction in residential aged care. International Journal for Quality in Health Care 14(1): 49-54.

De Jonge J (1995) Job Autonomy, Well-being and Health. Maastricht, the Netherlands: Rijksuniversiteit Limburg.

De Jonge J, Landeweerd JA and Nijhuis FJN (1993) Constructie en validering van de vragenlijst ten behoeve van het project 'Autonomie in het werk'. Maastricht, the Netherlands: Studies bedrijfsgezondheidszorg Maastricht University.

De Jonge J, Mulder MJGP and Nijhuis FJN (1999) The incorporation of different demand concepts in the job demand-control model: Effects on health care professionals. Social Science and Medicine 48(9): 1149-1160.

De Jonge J, Reuvers MMEN, Houtman ILD, et al. (2000) Linear and nonlinear relations between psychosocial job characteristics, subjective outcomes, and sickness absence: Baseline results from SMASH. Journal of Occupational Health Psychology 5: 256-268.

Edvardsson D, Sandman PO, Nay R, et al. (2008) Associations between the working characteristics of nursing staff and the prevalence of behavioral symptoms in people with dementia in residential care. International Psychogeriatrics 20(4): 764-776.

Eliopoulos C (2010) Guest editorial: Cultural transformation in nursing homes. International Journal of Older People Nursing 5(1): 1-2.

Ferri P, Guadi M, Marcheselli L, et al. (2016) The impact of shift work on the psychological and physical health of nurses in a general hospital: A comparison between rotating night shifts and day shifts. Risk Management and Healthcare Policy 9: 203-211.

Gilloran A, Robertson A, McGlew T, et al. (1995) Improving work satisfaction amongst nursing staff and quality of care for elderly patients with dementia: Some policy implications. Ageing \& Society 15: 375-391.

Johnson JV and Hall EM (1988) Job strain, work place social support, and cardiovascular disease. A cross-sectional study of a random sample of the Swedish working population. American Journal of Public Health 78: 1336-1342.
Kane RA, Lum TY, Cutler LJ, et al. (2007) Resident outcomes in small-house nursing homes: A longitudinal evaluation of the initial green house program. Journal of the American Geriatric Society 55: 832-839.

Karasek RAJ (1985) Job Content Instrument: Questionnaire and User's Guide, version 1.1. Department of Industrial and Systems Engineering, University of Southern California, Los Angeles, CA.

Kovner C, Brewer C, Wu Y, et al. (2006) Factors associated with work satisfaction of registered nurses. Journal of Nursing Scholarship 38(1): 71-79.

Landsbergis PA (1988) Occupational stress among health care workers: A test of the job demands-control model. Journal of Organizational Behavior 9(3): 217-239.

Larrabee JH, Wu Y, Persily CA, et al. (2010) Influence of stress resiliency on $\mathrm{RN}$ job satisfaction and intent to stay. Journal of Nursing Administration 33(5): 271-283.

Mattiasson A and Andersson L (1995) Organizational environment and the support of patient autonomy in nursing home care. Journal of Advanced Nursing 22(6): 1149-1157.

Niessen LW, Grijseels EW and Rutten FF (2000) The evidence-based approach in health policy and health care delivery. Social Science and Medicine 51(6): 859-869.

Norbergh KG, Hellzen O, Sandman PO, et al. (2002) The relationship between organizational climate and the content of daily life for people with dementia living in a group-dwelling. Journal of Clinical Nursing 11: 237-246.

Parker C, Barnes S, McKee K, et al. (2004) Quality of life and building design in residential and nursing homes for older people. Ageing \& Society 24: 941-962.

Pot A and De Lange J (2010) Monitor Woonvormen Dementie. Een studie naar verpleeghuiszorg voor mensen met dementie. Utrecht, the Netherlands: Trimbos-instituut.

Reggentin H and Dettbarn-Reggentin J (2004) Belastung wird durch Motivation kompensieren Wohngruppen für Menschen mit Demenz. Pflegezeitschrift 57(7): 489-493.

Rosen J, Mittal V, Degenholtz H, et al. (2005) Organizational change and quality improvement in nursing homes: Approaching success. Journal for Healthcare Quality 27(6): 6-14.

Spoor EMB, De Jonge J and Hamers JP (2010) Design of the DIRECT-project: Interventions to increase job resources and recovery opportunities to improve job-related health, well-being, and performance outcomes in nursing homes. BMC Public Health 10: 293.

Te Boekhorst S, Depla M, de Lange J, et al. (2007) Kleinschalig wonen voor ouderen met dementie: Een begripsverheldering. Tijdschrift voor Gerontologie en Geriatrie 38: 17-26.

Te Boekhorst S, Willemse B, Depla MFIA, et al. (2008) Working in group living homes for older people with dementia: The effects on job satisfaction and burnout and the role of job characteristics. International Psychogeriatrics 20(5): 927-940.

Temkin-Greener H, Zheng N, Cai S, et al. (2010) Nursing home environment and organizational performance: Association with deficiency citations. Medical Care 48(4): 357-364.

Verbeek H, van Rossum E, Zwakhalen SM, et al. (2009a) The effects of small-scale, homelike facilities for older people with dementia on residents, family caregivers and staff: Design of a longitudinal, quasi-experimental study. $B M C$ Geriatrics 9: 3.

Verbeek H, van Rossum E, Zwakhalen SM, et al. (2009b) Small, homelike care environments for older people with 
dementia: A literature review. International Psychogeriatrics 21(2): 252-264.

Verbeek H, Zwakhalen SM, van Rossum E, et al. (2010a) Dementia care redesigned: Effects of small-scale living facilities on residents, their family caregivers, and staff. Journal of the American Medical Directors Association 11(9): 662-670.

Verbeek H, Zwakhalen SM, van Rossum E, et al. (2010b) Small-scale, homelike facilities versus regular psychogeriatric nursing home wards: A cross-sectional study into residents' characteristics. BMC Health Services Research 29(10): 30.

Verbeek H, Zwakhalen SMG, van Rossum E, et al. (2012) Small-scale, homelike facilities in dementia care: A process evaluation into the experiences of family caregivers and nursing staff. International Journal of Nursing Studies 49: 21-29.

Vermeerbergen L, Van Hootegem G and Benders J (2017) A comparison of working in small-scale and large-scale nursing homes: A systematic review of quantitative and qualitative evidence. International Journal of Nursing Studies 67: 59-70.

White-Chu EF, Graves WJ, Godfrey SM, et al. (2009) Beyond the medical model: The culture change revolution in long-term care. Journal of the American Medical Directors Association 10(6): 370-378.

Willemse BM, De Jonge J, Smit D, et al. (2015) Staff's personcentredness in dementia care in relation to job characteristics and job-related well-being: A cross-sectional survey in nursing homes. Journal of Advanced Nursing 71(2): 404-416.

Willemse BM, Depla MF, Smit D, et al. (2014) The relationship between small-scale nursing home care for people with dementia and staff's perceived job characteristics. International Psychogeriatrics 26(5): 805-816.

Wimo A and Morthenson Ekelöf C (2004) OECD Case Study on Dementia. Stockholm, Sweden: Stiftelsen Stockholms Iäns Äldrecentrum.

Sandra MG Zwakhalen works as a professor of Nursing Science at the Department of Health Services Research at Maastricht University, the Netherlands.

Jan PH Hamers works as a professor of Care of Older People at the Department of Health Services Research at Maastricht University, the Netherlands.

Erik van Rossum works as a senior researcher at the Department of Health Services Research at Maastricht University and at the University of Applied Science Zuyd, Heerlen in the Netherlands.

Ton Ambergen works as a senior researcher at the Department of Statistics and Methodology at Maastricht University in the Netherlands.

Gertrudis IJM Kempen as a professor of Social Gerontology at the Department of Health Services Research at Maastricht University, the Netherlands.

Hilde Verbeek works as a senior researcher at the Department of Health Services Research at Maastricht University in the Netherlands. 